\title{
Selective applications of some extero- and interoceptive biofeedback devices
}

\author{
THOMAS S. BALL \\ Fairview State Hospital, Costa Mesa, California 92626
}

\begin{abstract}
A number of highly innovative uses for biofeedback devices in mental health care delivery settings are described. These devices are portable and are carried by the client. Exteroceptive or interoceptive sensors are used to automatically deliver feedback about behaviors. The experiments reviewed here demonstrate some of the many treatment possibilities available with remote biofeedback equipment.
\end{abstract}

For several years, we have been developing lightweight portable biofeedback devices that can be attached to and carried by the client without interfering with his normal daily activities in school or in the institution. The first consisted of a mercury switch connected to an inexpensive transistor radio, which reinforced upright head orientation of a blind retarded girl in a classroom setting (Ball, 1971) and of two institutionalized retarded children with severe cerebral palsy (Ball, McCrady, \& Hart, 1975). We then experimented with a different kind of exteroceptive sensor, the accelerometer, which automatically triggered a batteryoperated shock device whenever the client administered assaultive blows to himself or others (Ball, Sibbach, Jones, Steele, \& Frazier, 1975). A scheduling capability was introduced with the addition of a timing device that permitted automatic monitoring of client behaviors on a DRO schedule. In a study with a nonretarded hyperactive child treated in a special education classroom (Ball \& Irwin, 1976), the timer-controlled buzzer was automatically activated at the end of $2-\mathrm{min}$ periods of continuous sitting. The child pressed a reset button that started a new timing cycle and then recorded a check mark that was later redeemable for 1 cent. If the child arose before the end of the $2 \mathrm{~min}$, a mercury switch triggered the timer, resetting and holding it at zero until he resumed sitting. The same device was used with two institutionalized retarded individuals. Specifically, an orthopedically handicapped child was trained to stand independently, and an adult learned to inhibit stereotypic rocking (Ball, McCrady, \& Teixeira, 1978). In this and subsequent studies, responsibility for resetting the buzzer was assigned to the attending adult. Most recently, we have developed a portable, interoceptive, that is, electromyographic (EMG), version of the mercury switchactivated DRO device. If the subject relaxes the monitored muscle group below a preset threshold for a specified interval, a buzzer activates and is reset as noted

Requests for reprints should be addressed to Thomas S. Ball, Fairview State Hospital, 2501 Harbor Boulevard, Costa Mesa, California 92626 . above. ${ }^{1}$ With only a slight modification, this device can be used to train voluntary muscle activation rather than relaxation.

We have also used a joint switch, based on a goniometer, to train range of motion for two cerebral palsied retarded young men (Ball, Combs, Rugh, \& Neptune, 1977). We have also conducted automated finger praxis training with a severely cerebral palsied, adolescent woman (Ball \& McCrady, 1975). She wore metal thimbles connected to a (nonportable) programming apparatus that activated lights with each sequential thumb-finger contact. ${ }^{2}$

Even in settings in which staff members are available to monitor clients continuously, automated devices have some inherent advantages. Because these mechanisms are worn in the natural environment and stimulus control becomes attached to the device itself, behavioral control readily generalizes across settings and people. For example, Ball, Sibbach, Jones, Steele, and Frazier (1975), with their accelerometer-activated shock device, attained generalization not found in previous research involving cattle prods (Lovaas \& Simmons, 1969; Risley, 1968). And since the role of punishing agent is assigned to the equipment rather than the staff, the latter are free to concentrate on rewarding rather than punishing clients. They can also avoid the possibly dangerous physical altercations associated with the application of a hand-held inductorium as well as the concomitant danger of conditioning a masochistic response. Punishment is administered "in a matter of fact way," as Bandura (1969, p. 318) recommended, and probably with less emotional stress on the staff. This technique maximizes features critical to treatment effectiveness, such as immediacy and consistency of punishment (Gardner, 1971, p. 299). Using accelerometers connected to electronic counters, it is possible to quantitatively measure those decreases in impact that are frequently associated with the successful treatment of self-injurious hitting. Also, with accelerometers instead of mercury switches to trigger the previously mentioned DRO device, positive reinforcement of nonhitting can be programmed. 


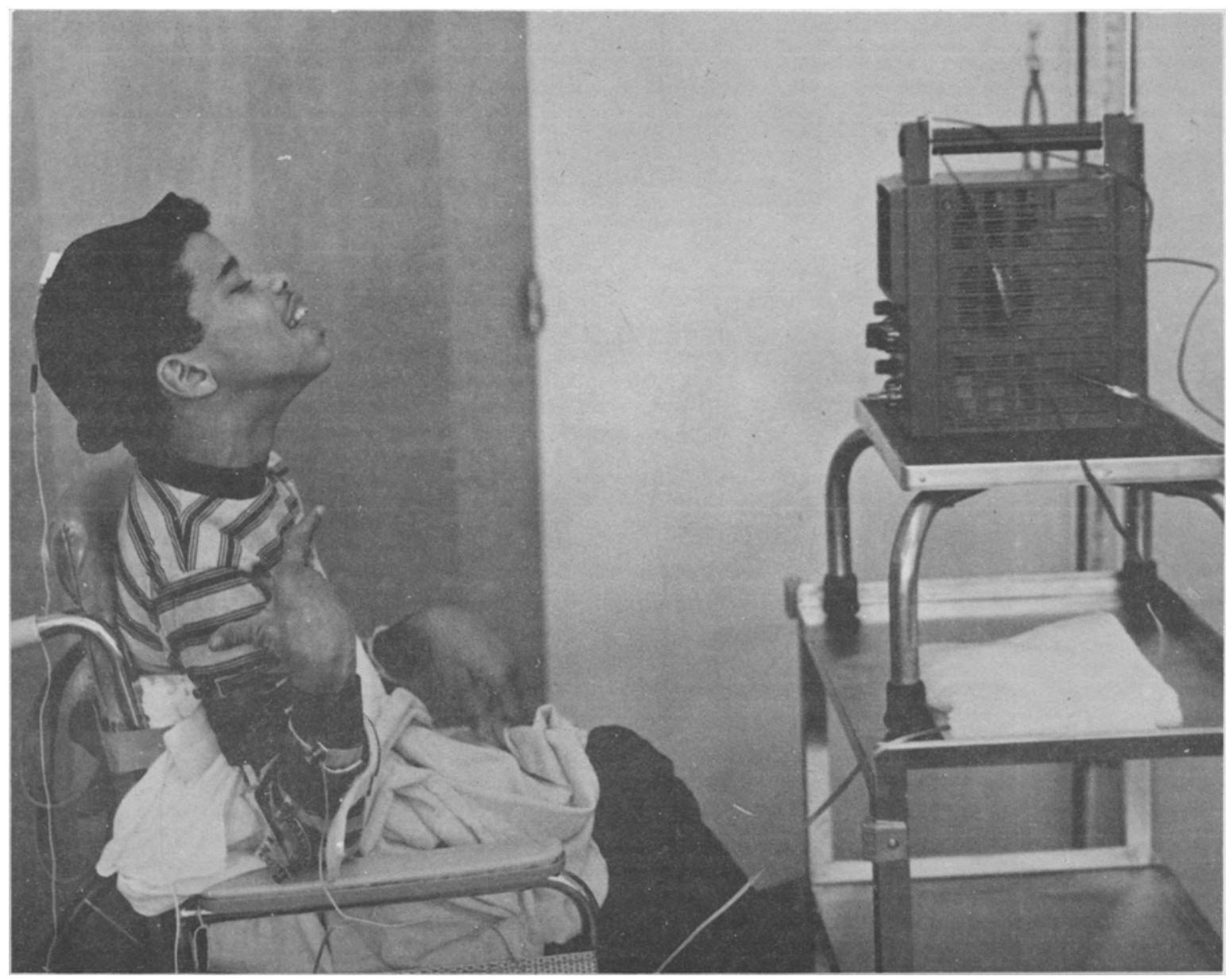

Figure 1. Subject with biofeedback attachments watching a television screen. Note sensors on head and elbow/arm.

Sometimes, biofeedback devices in combination can achieve clinical goals unattainable with one biofeedback device alone. For example, a cerebral palsied client may use a primitive, generalized extension pattern to effect upright head orientation and activation of the mercury switch/radio apparatus. Instead of accomplishing differentiated, voluntary muscle activation, the client reverts to an abnormal reflexive pattern that may actually impede the subsequent development of normal reflexes (see Bobath, 1967). To encourage adaptive learning, we have connected the mercury switch in series with the joint switch. As Figure 1 reveals, the client's head extension must be combined with arm flexion to activate the portable television. This precludes the appearance of a primitive, undifferentiated extension of the whole body. (Note that a mercury switch circuit should not be attached to a television without the assistance of a qualified electronics technician.)

In a recent study (Ball, Campbell, \& Barkemeyer,
1980), air splints were worn on the arms of a profoundly retarded young woman to suppress prolonged, stereotypic finger sucking that had produced salivary dermatitis. With the markedly reduced rate of finger sucking produced by the air splints, it was feasible to add the DRO device and effectively reinforce incompatible behaviors. The combined approach enabled us, for the first time, to fade air pressure to zero, without losing behavioral control. This study also illustrates how one kind of sensor can be used to monitor diverse forms of movement in the same subject. Thus, by attaching mercury switches to both the wrists and the shoulder, it was possible to monitor body rocking and hand elevation simultaneously and to receive a signal to reinforce the subject when neither occurred for a specified interval.

Applied behavior modification can be enhanced and extended through the proper use of machines. Our experience suggests that, with the aid of technology, 
staff can effectively and efficiently conduct interventions that would otherwise be infeasible. We have scarcely begun to realize the benefits of this approach.

\section{REFERENCES}

Bald, T. S. Comments: Blindism. In T. S. Ball (Ed.), A guide for the instruction and training of the profoundly retarded and severely multi-handicapped child. Santa Cruz, Calif: Santa Cruz County Office of Education, June 1971.

Ball, T. S., Campbell, R., \& Barkemeyer, R. Air splints applied to control self-injurious finger sucking in profoundly retarded individuals. Journal of Behavior Therapy and Experimental Psychiatry, 1980, 11, 267-271.

Ball, T. S., Combs, T., Rugh, J., \& Neptune, R. Automated range of motion training. Mental Retardation, 1977, 15, 47-50.

Ball, T. S., \& Irwin, A. E. A portable, automated device applied to training a hyperactive child. Journal of Behavior Therapy and Experimental Psychiatry, 1976, 7, 185-187.

BALL, T. S., \& MCCRADY, R. E. Automated finger praxis training with a cerebral palsied retarded adolescent. Mental Retardation, 1975, 13, 41.

Ball, T. S., McCrady, R. E., \& Hart, A. D. Automated reinforcement of head posture in two cerebral palsied retarded children. Perceptual and Motor Skills, 1975, 40, 619-622.

Ball, T. S., McCrady, R. E., \& TEixeira, J. Automated monitoring and cuing for positive reinforcement and differential reinforcement of other behavior. Journal of Behavior Therapy and Experimental Psychiatry, 1978, 9, 33-37.

Ball, T. S., Sibbach, L., Jones, R., Steele, B., \& Frazier, L. An accelerometer-activated device to control assaultive and selfdestructive behaviors in retardates. Journal of Behavior Therapy and Experimental Psychiatry, 1975, 6, 223-228.

Bandura, A. Principles of behavior modification. New York: Holt, Rinehart, \& Winston, 1969.

Boв ath, B. The very early treatment of cerebral palsy. Developmental Medicine and Child Neurology, 1967, 9, 373-390.

Gardner, W. I. Behavior modification in mental retardation. Chicago: Aldine Atherton, 1971.

LovaAs, O. I., \& Simmons, J. Q. Manipulation of self-destruction in three retarded children. Journal of Applied Behavior Analysis, $1969,2,143-157$.

Risley, T. The effects and side effects of punishing the autistic behavior of a deviant child. Journal of Applied Behavior Analysis, 1968, 1, 21-34.

\section{NOTES}

1. For more information on both the intero- and exteroceptive versions of this device, contact Advanced Electro Labs, 366 South Lemon Avenue, Walnut, California 91789.

2. The concept of this device was suggested by Valerie Ackerland of Lanterman State Hospital, Pomona, California. 